\title{
Acute Postpartum Pulmonary edema: A Case Report
}

\author{
NAHREEN AKHTAR ${ }^{1}$, NAMKHA DORJI², TABASSUM PARVEEN ${ }^{3}$ YESHEY DORJEY², \\ FIROZA BEGUM ${ }^{4}$, SAMIRA HAYEE $^{5}$, SABINA KARIM ${ }^{6}$
}

\begin{abstract}
:
A 30 year old, $G_{2} P_{1}$, pregnancy complicated with moderate anaemia, preeclampsia and gestational diabetes mellitus was admitted at $37^{+}$week pregnancy with less fetal movement and premature rupture of membrane. A healthy baby was delivered by caesarean section with uneventful perioperative period. On $4^{\text {th }}$ post operative day, she developed severe acute pulmonary edema where intubation was done instantly and ventilated in the intensive care unit. Patient recovered and extubation done on $6^{\text {th }}$ postoperative day. A healthy mother and a healthy baby were discharged on $10^{\text {th }}$ postoperative day.
\end{abstract}

Key words: Pulmonary edema, post partum

\section{Introduction:}

Postpartum pulmonary edema is an uncommon but a life threatening event in pregnancy which causes significant morbidity and mortality in women with preeclampsia. The Scottish Confidential Audit of Severe Maternal Morbidity, one of the largest maternal morbidity audits, reported that acute pulmonary edema was the fourth most common cause of maternal morbidity. ${ }^{1}$ It is also frequently the reason for intensive care admission ${ }^{2}$, and may occur during the antenatal, intrapartum or postpartum periods. The mechanism of acute pulmonary edema depends on hemodynamic state of pregnant women. Cardiac structural and functional abnormalities along with alterations in fluid balance and proteinuria may be the cause. Acute hypertensive crisis that cause pulmonary edema may occur through sympathetic nervous activation, causing acute venoconstriction and vasoconstriction, which leads to

increased afterload and redistribution of fluid from peripheral circulation to pulmonary vessels. This causes alveolar fluid accumulation and reduced oxygenation and increase in cardiac output due to reduce oxygen delivery to kidney. Unrestricted fluid administration is recognized as significant risk factor for developing acute pulmonary edema. A high degree of clinical suspicion in a patient with acute respiratory distress, and proper auscultation of lungs supported by chest $X$ ray is the cornerstone of diagnosis. Multidisciplinary team approach with intensive care unit (ICU) facility is required to save life of patients with severe acute pulmonary oedema. Herein, we report a case of a severe life threatening postpartum pulmonary oedema in a young female who had preeclampsia, gestational diabetes mellitus and moderate anaemia.

\section{Case Report:}

A 30 year old woman, $\mathrm{G}_{2} \mathrm{P}_{1}$, was admitted to the Fetomaternal Unit, Department of Obstetrics and Gynaecology, Bangabandhu Sheikh Mujib Medical (BSMMU) at $37^{+}$weeks of gestation with less fetal movement for last 8 hours and per vaginal watery discharge for last 3 days. She was diagnosed as a case of preeclampsia and gestational diabetes mellitus since 28 weeks gestation. She was on Tab. Alpha Methyldopa 250mg TDS and short acting insulin (Actrapid) 4+6+8 units for preeclampsia and gestational diabetes mellitus respectively, which were

1. Professor, Department of Fetomaternal Medicne, BSMMU, Dhaka.

2. Resident (Phase B), Department of Obstetrics and Gynaecology, BSMMU, Dhaka.

3. Associate Professor, Department of Fetomaternal Medicine ,BSMMU, Dhaka

4. Chairman, Department of Fetomaternal Medicine ,BSMMU, Dhaka

5. Internee, Chottogram medical College, Chottogram

6. Junior consultant (Paediatrics), Kurmitola General Hospital, Dhaka Cantonment, Dhaka.

Address of Correspondence: Prof. Nahreen Akhtar, Professor, Department of Fetomaternal Medicne, BSMMU, Dhaka. E-mail: nahreenakhtar10@gmail.com, Cell: 01711544687. 
under good control. She was anaemic, pulse rate was 80 beats per minute and blood pressure was $140 / 90 \mathrm{mmHg}$. Mild bilateral pitting ankle oedema was present. Clinical examination confirmed viable fetus with premature rupture of membrane with breech presentation. Review of her antenatal history and investigations records revealed that she was on routine follow up at our Outpatient Department (OPD).

An elective lower uterine caesarean section (LUCS) under spinal anaesthesia was performed on the next day. A live male baby weighing 2600 gram was delivered. Her postoperative recovery was uneventful up to day 3. However, her postoperative haemoglobin was $7.7 \mathrm{~g} / \mathrm{dl}$ and she was transfused 2 units of packed red cells. Her preoperative haemoglobin was $9.0 \mathrm{~g} /$ dl. Her blood pressure was controlled with Cap Nidipro (Atenolol $50 \mathrm{mg} \&$ sustained release Nifedipine $20 \mathrm{mg}$ combination) BD and blood sugar by injection Actrapid insulin 100iu/ml 4 units TDS subcutaneously.

On fourth postoperative day, she developed sudden onset severe respiratory distress: she was gasping, cyanosed, GCS (Glasgow Coma Scale) was 3/15, pulse rate was $110 \mathrm{bpm}$, blood pressure was 190/ $110 \mathrm{mmHg}$, crepitation was present in bilateral lung fields. A provisional diagnosis of acute postpartum pulmonary edema was made. SpO2 on air dropped to $21 \%$. On administering $\mathrm{O}_{2}$ at $15 \mathrm{~L} / \mathrm{min}$ via facemask, SpO2 was $50 \%$. She was given intravenous hydrocortisone $200 \mathrm{mg}$ and intravenous furosemide $60 \mathrm{mg}$ ( 3 ampoules). She was intubated immediately and shifted to the intensive care unit, BSMMU. A urinary catheter was inserted and urine output monitored.

ABG (arterial blood gas) showed $\mathrm{pH}$ of $7.368, \mathrm{Hb}-$ $9.2 \mathrm{~g} / \mathrm{dl}$, no ischemic changes in the ECG, urine protein was ++ . Chest $X$ ray massive pulmonary congestion. Echocardiograph showed good LV function with EF of $67 \%$. Cardiac enzyme (Troponin I) was negative.

In the ICU, oxygen saturation was maintained at $100 \%$. She was managed with intravenous antibiotics (Injection Ceftriaxone 1g 12 hourly, Injection metronidazole $500 \mathrm{mg} 8$ hourly and injection gentamicin $80 \mathrm{mg} 8$ hourly). Intravenous furosemide was continued. Her BP was controlled with intravenous Labecard (Labetalol) 200mg 12 hourly. Her blood sugar was monitored closely and maintained with subcutaneous Actrapid insulin. Her clinical condition improved.
The ventilation was weaned off on day 6 as her condition improved. Healthy mother with a healthy baby were discharged on postoperative day 10 .

She came to follow up on $28^{\text {th }}$ Feb 2016. Blood pressure was under controlled with Tab Nidipro. The follow up echocardiograph revealed EF-67\% and there was no evidence of cardiac pathology. She did not have any complaint.

\section{Discussion:}

Acute pulmonary edema is a life threatening condition that occurs more often in pregnancies than in non pregnant state. It complicates about $0.08 \%$ of pregnancies. ${ }^{3}$ Based on patient presentation with acute postpartum dyspnoea, these condition can be categorised into pathologies not associated with pulmonary oedema (pulmonary embolism, sepsis and aspiration of gastric content) and pathologies associated with pulmonary oedema include cardiogenic and noncardiogenic causes. Noncardiogenic pulmonary edema include iatrogenic fluid overload, thyroid disease, drug induced pulmonary edema (e.g., tocolytic therapy and oxytocin), acute respiratory distress syndrome (ARDS), and preeclampsia related pulmonary edema. Peripartum cardiomyopathy, preeclampsia induced cardiomyopathy, underlying structural heart diseases or valvular heart diseases, and myocardial ischemia are examples of cardiogenic causes of pulmonary edema. ${ }^{4}$

Disturbance in any of the key determinates of cardiovascular function and fluid flow into the pulmonary interstitium could result in acute pulmonary edema. ${ }^{5}$

Acute pulmonary edema can occur in antenatal, intrapartum and postpartum periods. Patients present with sudden onset acute respiratory distress. It is a frequent reason for intensive care unit admission. ${ }^{2}$

Provision of symptomatic relief, improvement of oxygenation, maintenance of cardiac output, perfusion of vital organs and reduction of excess extracellular fluid constitute the goals of treatment of acute pulmonary edema. Underlying cause has to be identified and targeted treatment initiated. Nitrates, diuretics, morphine and inotropes are drugs needed for treatment. Ventilator support is required for some cases. ${ }^{6}$

Intraveneous furosemide (bolus 20 - 40mg over 2 minutes) is used to promote venodilation and diuresis 
with repeated doses of 40-60mg after approximately 30 minutes if there is an inadequate diuretic response (maximum dose 120mg). ${ }^{7}$ In this case we managed with $60 \mathrm{mg}$ of furosemide initially. Some studies have demonstrated doubtful benefit of diuretics in acute pulmonary edema. Intravenous furosemide ranging from 40-80 $\mathrm{mg}$ can be administered in patients with fluid overload. It should be used judiciously in patients with volume depletion as furosemide causes reduction in preload. ${ }^{8}$

There is a reported case of delayed postpartum preeclampsia causing acute postpartum dyspnoea which is uncommon. ${ }^{4}$ In our case, patient developed acute pulmonary edema on $4^{\text {th }}$ postoperative day. She had known risk factors that would precipitate acute pulmonary edema: severe preeclampsia and anemia. However, the anemia was corrected by transfusing two units of packed red cells. she was given intravenous infusion of oxytocin and intravenous fluid in the post operative period. Oxytocin has been reported to cause water intoxication with high accumulative doses (40-50 units accumulative doses) in conjunction with large volume of intravenous fluid. As oxytocin has short half life of several minutes only and the total dose of oxytocin administered was low, acute pulmonary edema in this case is unlikely due to oxytocin infusion. Moreover, her symptoms developed on $4^{\text {th }}$ postoperative day.

Combination of multiple factors could have resulted in acute pulmonary edema. A study showed development of pulmonary edema in $17.3 \%$ of preeclamptic patients. ${ }^{9}$ Proper monitoring of early features of onset of pulmonary oedema and administration of prophylactic intravenous furosemide could have prevented the unfortunate near miss event. However, prompt recognition and timely treatment saved a life which is a satisfying memory for the treating obstetricians.

\section{Conclusion:}

Any obstetric patient with acute respiratory distress syndrome is a life threatening medical emergency which should be urgently evaluated with detailed history, clinical examination and relevant investigations. Appropriate and early management by involving multidisciplinary team would improve the outcome.

An obstetrician caring pregnant women should have knowledge on causes, mechanism and management protocol for such patients. A vigilant monitoring and taking prophylactic measures to prevent development of acute pulmonary edema in those women at risk would be an ideal situation.

\section{References:}

1. Centre for Maternal and Child Enquiries (CMACE). Saving Mothers' Lives: reviewing maternal deaths to make motherhood safer: 2006-08. The Eighth Report on Confidential Enquiries into Maternal Deaths in the United Kingdom. BJOG 2011;118(Suppl. 1):1-203.

2. Pollock W, Rose L, Dennis CL. Pregnant and postpartum admissions to the intensive care unit: a systematic review. Intensive Care Med (2010) 36:1465-1474. doi:10.1007/s00134010-1951-0.

3. Sciscione AC, Ivester T, Largoza M, Manley J, Shlossman P, Colmorgen GH. Acute pulmonary edema in pregnancy. Obstet Gynecol 2003;101:511-5.

4. Prueksaritanond S, Ali AM, Aronu, GN, Hussain N, Ganjoo A, Mirrakhimov AE, Barbaryan A. An uncommon cause of shortness of breath in a young puerperal. Case Reports in Obstetrics and Gynecology. Volume 2013, Article ID 710620, 4 pages http://dx.doi.org/10.1155/2013/ 710620.

5. Despopoulos A, Sibernagl. Color Atlas of Physiology $4^{\text {th }}$ ed. Stuttgard and Newyork: Georg Thieme Verlag and Thieme Inc, 1991.

6. Purvey M, Allen G. Managing acute pulmonary oedema. Aust Prescr 2017;40:59-63. http:// dx.doi.org/10.18773/austprescr.2017.013.

7. Nieminen MS, Bohm M, Cowie MR. Drexler H, Filippatos GS, et al. Executive summary of the guidelines on the diagnosis and treatment of acute heart failure: The Task Force on Acute Heart Failure of European Society of Cardiology. European Heart Journal (2005) 26, 384-416 http://dx.doi:10.1093/eurheartj/ehi044.

8. Acute cardiogenic pulmonary oedema. In: eTG complete. Melbourne: Therapeutic Guidelines Limited; 2016. Available from: https:// www.tg.org.au/.

9. Motwani M M, Shah S S, Mehta AC. Pulmonary edema in severe pre-eclampsia (a case report). J Postgrad Med 1989;35:183. Available from: http://www.jpgmonline.com/ text.asp?1989/35/3/183/5691 